Article

\title{
New Formula for the Identification of Liquefaction Based on
}

\section{the Investigation of the Songyuan Site}

\author{
Ping $\mathrm{Li}^{1,2,3, *}$, Yuan Zhang ${ }^{2,3}$ and Yudong Zhang ${ }^{2,3}$ \\ 1 School of Engineering Consulting\&Design,Northeast Forestry University,Harbin 150040 Heilongjiang China. \\ 2 Department of Geological Engineering Institute of Disaster Prevention, Sanhe 065201, Hebei, China. \\ 3 Hebei Key Laboratory of Earthquake Disaster Prevention and Risk Assessment, Sanhe 065201. \\ * Correspondence: Ping Li.chinaliping1981@126.com; CHN
}

\begin{abstract}
Based on the 5.7-magnitude earthquake that stroke Songyuan (China) and 172 groups of liquefaction data collected in mainland China, the hyperbolic liquefaction discriminant formula originally proposed by Sun Rui was revised, and a new formula for the liquefaction of sand was put forward. Groups of data derived from the Bachu earthquake in Xinjiang and an earthquake that occurred in New Zealand (47 and 195 groups, respectively) were used to carry out a back-judgment test, then, the results were compared with those of the existing standard method. Overall, the results showed that the new formula for hyperbolic liquefaction discrimination compensates for the conservative liquefaction discrimination of the older formula; moreover, it has a good applicability to different intensities, groundwater levels, and the deep sand layer of the Songyuan site, reflected by a more balanced success rate. Therefore, combining the existing liquefaction discrimination methods and the research results of discrimination, it is necessary to establish a suitable regional identification method through the continuous accumulation of liquefaction data and expanding database.
\end{abstract}

Keywords: Songyuan earthquake; Songyuan site; sand liquefaction; hyperbolic model; discriminant formula

\section{Introduction}

It has been shown that sand soil liquefaction is a kind of destructive and certain regional seismic disaster through the earthquake damage investigation at home and abroad. Large-scale sand liquefaction will destroy infrastructure such as roads, bridges, industrial facilities, civil buildings, and water conservancy projects, resulting in loss of foundation bearing capacity, uneven settlement, slope slip, and several catastrophic damages. Therefore, scholars at home and abroad have studied the liquefaction mechanisms, as well as the influencing factors and possible discriminant methods. Their findings have allowed an effective reduction of the disasters caused by sand liquefaction [18, 31-32].

In actual engineering investigations, sand liquefaction discriminations are carried out at the engineering sites, and the effective foundation treatment of the site (done according to the discriminant results) can effectively reduce the liquefaction disaster of sandy soil, so the reliability of the sand liquefaction discrimination method applied is vital. Hence, with the accumulation of seismic data, the accuracy with which liquefaction sites can be identified will gradually improve. [28] It is important to improve the sand liquefaction discrimination method based on sand liquefaction data collected at earthquake sites On May 28, 2018 AM01:50:52, in Songyuan City (Jilin Province, Ningjiang District, Maodu Station Town), a 5.7-magnitude earthquake occurred. Post-earthquake investigations [9] have shown that, in this location, farmland covered by sand, housing settlements and gable walls cracked, etc. was caused by sand liquefaction. The day after the earthquake, a field team of more than ten people from the Institute of Disaster Prevention entered the earthquake area. The phenomenon of sand liquefaction was investigated in detail (e.g., 
through field surveys, drilling, shear-wave velocity tests, and static penetration). In this way, it was possible to estimate the seismic damage, the site characteristics in the epicenter area, and the liquefaction of sand 1 during the seismic event. In this paper, based on the sand liquefaction data collected for the Songyuan 5.7-magnitude earthquake and on 172 groups of basic liquefaction data collected through the standard penetration method, the hyperbolic liquefaction discriminant formula was established. The variables of formula are groundwater level, buried depth, and the standard penetration hammer number.

By investigating the large-scale sand liquefaction caused by the Xingtai, Tonghai, Haicheng, and Tangshan earthquakes in the 1960s and 1970s through post-earthquake field surveys, it has been possible to accumulate a large amount of liquefaction data. A method for sand liquefaction discrimination in China, based on such data, was first published in the "Code for Seismic Design of Industrial and Civil Buildings" (TJ11-78) [10]. This method was continuously improved and gradually evolved in the "Building Seismic Design Code" (GB50011-2010) discrimination method. In the "Code for Seismic Design of Buildings" (GB50011-2010) a method for involving the use of a standard penetration hammer number (based on the "Code for Seismic Design of Industrial and Civil Buildings", TJ11-78) is proposed. The method proposed in the "Code for Seismic Design of Industrial and Civil Buildings" (TJ11-78), instead, only considers the effect of seismic intensity on liquefaction. In the "Code for Seismic Design of Buildings" [11], the liquefaction discrimination presented in GBJ11-89 is considered suitable for the discrimination of liquefaction within the upper $15 \mathrm{~m}$ of sand. Since the foundation burial depth established by this code is only three depths of more than $10 \mathrm{~m}$ for statistical analysis (The data were selected from the damage investigation results of the Tangshan earthquake and Haicheng earthquake in China), the discriminant formula is only suitable for sand layers at a maximum depth of 10m. The "Code for Seismic Design of Buildings" [12] (GB50011-2001) proposes the use of a pre-standard discriminant formula to investigate soil liquefaction within $15 \mathrm{~m}$ depth, when soil liquefaction is identified between $15-20 \mathrm{~m}$ depth, a depth of $15 \mathrm{~m}$ would be considered and directly applied to the discriminant formula, which is not related with the buried depth of the liquefied soil layer, however the critical value of liquefaction cannot be determined from a straight linear function. In the "Code for Seismic Design of Buildings [13]" (GB50011-2010), the critical value of liquefaction discrimination is determined from a continuous nonlinear function. The shape of the critical standard penetration curve of the standard method is mainly controlled by the shallow data points. Notably, the variation rate of the liquefaction critical value (critical hammering value) is faster even when the soil layer depth greater than $10 \mathrm{~m}$, resulting in a critical hammering value of 37 at 20 $\mathrm{m}$. The current recognition liquefied samples with more than 30 blows were not found, so the judgment method is conservative.

A method for the determination of liquefaction in saturated sandy soil was proposed by Seed, etc [20]. By the horizontal shear-stress under actual seismic action divided by the anti-liquefaction shear stress of sandy soil, they were able to evaluate in detail sandy soil liquefaction. The method proposed in the "Code for Seismic Design of Industrial and Civil Buildings promulgated by China" [10] (TJ11-78) provided similar results. Experts convened by Idriss and Yound (1998) to study the data of the past 10 years[2], the Seed simplification method is introduced in more detail[19]. Based on the simplification method of Seed, a simplified discriminant method and a new concept of liquefaction safety factor (1.0 being the reference value for liquefaction discrimination) were proposed in the "Japanese Road and Bridge Seismic Design Code" [22]; here, moreover, a simplified liquefaction analysis experience chart was established based on the standard penetration stroke number, which is published by "European Seismic Design Code 8"[22]. However, when applying the above method, the critical standard penetration value was found to abnormally decrease with the increase of depth; the critical standard penetration curve of soil in the XIII intensity region maybe retracted and Seed's discriminant method tends to be conservative. 


\section{Hyperbolic discriminant formula for liquefaction discrimination}

\subsection{Data sources}

Based on the analysis of the deficiency of the existing discriminant formula, 172 sets of raw data of the discriminant formula of the "Code for Seismic Design of Buildings" (GB50011-2010) [23] and 26 sets of drilling data are formed at the Songyuan seismic site [9]. Based on the groundwater and soil depth data, as well as on the standard penetration hammer number, the liquefaction criterion formula is established. The distribution of the liquefaction data in different seismic regions is shown in Tables 1 and 2.3. Results

This section may be divided by subheadings. It should provide a concise and precise description of the experimental results, their interpretation, as well as the experimental conclusions that can be drawn.

Table 1. Data source and distribution of the liquefaction in mainland China

\begin{tabular}{ccccc}
\hline Earthquake name & $\begin{array}{c}\text { Year of } \\
\text { occurrence }\end{array}$ & $\begin{array}{c}\text { Earthquake } \\
\text { magnitude }\end{array}$ & $\begin{array}{c}\text { Seismic } \\
\text { intensity }\end{array}$ & Number of points \\
\hline Hejian earthquake & 1967 & 6.3 & 6 & $2(2)$ \\
Xingtai earthquake & 1966 & 6.7 & $7-8$ & $10(3)$ \\
Bohai Sea earthquake & 1969 & 7.4 & 7 & $4(4)$ \\
Yangjiang earthquake & 1969 & 6.4 & 7 & $4(3)$ \\
Heyuan earthquake & 1962 & 6.4 & 8 & $1(0)$ \\
Xingtai earthquake & 1966 & 7.2 & 9 & $8(7)$ \\
Tonghai earthquake & 1970 & 7.8 & $8-10$ & $39(18)$ \\
Haicheng earthquake & 1975 & 7.3 & $7-8$ & $12(7)$ \\
Tangshan earthquake & 1976 & 7.8 & $7-9$ & $92(55)$ \\
Songyuan earthquake & 2018 & 5.7 & 7 & $26(6)$ \\
\hline
\end{tabular}

Note: Values in parentheses indicate the number of liquefaction points

Table 2. Liquefaction data distribution in different intensity zones

\begin{tabular}{cccc}
\hline \multirow{2}{*}{ Intensity } & \multicolumn{3}{c}{ Number of points } \\
\cline { 2 - 4 } & Liquefied & Non-liquefied & Total \\
\cline { 2 - 4 } VI & 2 & 0 & 2 \\
VII & 34 & 46 & 80 \\
VIII & 28 & 27 & 55 \\
IX & 40 & 20 & 60 \\
X & 1 & 0 & 1 \\
Total & 105 & 93 & 198 \\
\hline
\end{tabular}

\subsection{Establishment of a discriminating formula for the double curve}

When the independent variable was small, the dependent variable increased rapidly with the increase of the former. However, when the independent variable increased to a certain extent, gradually tending to infinity, the increase rate of the dependent variable diminished with the increase of the former variable. Based on the advantages that the hyperbolic model conforms to the change of the liquefaction critical value with the depth of the soil layer, the hyperbolic shear wave velocity discriminant model and the discriminant formula are established for the liquefied soil layers of different depths by Sun Rui [26], 
and the hyperbolic model was used to study the pore pressure growth. The variation law of the coefficients in the dynamic constitutive relationship of the liquefied soil layer was developed by Sun Rui et al. [27]. In this paper, based on the formation of standard penetration discriminant method of liquefaction basic data ${ }^{[23]}$, the hyperbolic model discriminant formula for liquefaction discrimination was established, and the hyperbolic model discriminant formula was used to verify the data of different seismic sites.

The basic formula (Equation (1)) for liquefaction discrimination at the Songyuan site was constructed by using 198 sets of liquefaction data ( 172 sets of liquefaction basic data obtained through the standard penetration method and 26 sets of Songyuan seismic drilling data):

$$
N_{c r}=N_{0}^{\prime} d_{\omega} \frac{d_{s}}{d_{s}+k_{1}}
$$

where $\mathrm{N}_{c r}$-the critical value of the standard penetration hammer number, $\mathrm{d}_{s}-$ the buried depth(m), $\mathrm{d}_{\omega}$-the groundwater level(m), and $k_{1}-$ a parameter to be determined, $N_{0}^{\prime}$ - a standard penetration hammer reference value.

According to equation (1), when $\mathrm{d}_{s}$ takes $0, \mathrm{~N}_{c r}$ is 0 . The surface soil layer has been considered to be not liquefied. Since this assumption is inconsistent with actual engineering situations, the correction coefficient about the reference value of the standard penetration hammer number $\left(k_{2}\right)$ needs to be included in Equation (1). If the critical value of the standard penetration hammer number decreases gradually when the local groundwater level increases, the influence coefficient about the buried depth of the groundwater level ( $\left.k_{3}\right)$ should be included relatively to the reference value of the standard penetration hammer number in Equation (1). Therefore (1) is further:

$$
N_{c r}=N_{0}^{\prime}\left(1+k_{3} d_{\omega}\right)\left[k_{2}+\frac{d_{s}}{d_{s}+k_{1}}\right]
$$

where $\mathrm{k}_{2}$-the soil depth. when is 0 , the influence coefficient about the critical initial value of the standard penetration hammer number, $\mathrm{k}_{3}$-the influence coefficient of the groundwater's depth.

\subsection{Parameter selection}

The ranges of the three undetermined coefficients in the formula should meet the following requirements. (1) As regards the depth of groundwater level $(\mathrm{d} \omega)$, if the critical value of the standard penetration hammer number increases with the increase of the soil layer depth, then $\mathrm{k}_{1}$ is greater 0 . (2) When the groundwater level $\left(\mathrm{d}_{\omega}\right)$ and soil depth $\left(\mathrm{d}_{\mathrm{s}}\right)$ are 0 , the value range of the correction coefficient $k_{2}$ of the standard penetration hammer number reference initial value is $0-1$. (3) When the soil depth is constant, the critical value of the standard penetration hammer number decreases with the increase of the groundwater level. It is negatively correlated with the groundwater level, then $\mathrm{k}_{3}$ is less than 0 .

After selecting the survey and test points at the seismic sites, statistical analysis was been done about the buried depth of the groundwater and the depth of the liquefaction investigation layer; furthermore, the standard penetration hammer number was determined at different depths to obtain the critical values of the liquefaction and non-liquefaction points. The reference value of the standard penetration hammer number $N_{0}^{\prime}$ obtained from the regression analysis is shown in Fig. 1. For accelerations of $0.15 \mathrm{~g}, 0.2 \mathrm{~g}$ and $0.4 \mathrm{~g}$ the reference values were between $13-20,20-26$, and 34-40, respectively.

In the new discriminant formula, $N_{0}^{\prime}$ represents the range of reference values about the three undetermined coefficients, while the standard penetration hammer numbers have to be determined. In this study, 198 groups of measured data samples were regressed to obtain the optimal solution. The hyperbolic discriminant formula of site liquefaction in 
the Songyuan planning area (hereinafter referred to as "hyperbolic discriminant formula") was hance obtained (Equation (3)):

$$
N_{c r}=N_{0}^{\prime}\left(1-0.04 d_{\omega}\right)\left[0.29+\frac{d_{s}}{d_{s}+11.5}\right]
$$

where the value of $N_{0}^{\prime}$, it was calculated according to Table 3 . When using the above equation for liquefaction discrimination, only if the measured standard penetration hammer number of the sand layer is lower than the critical value of the standard penetration hammer number, it is judged as liquefaction, otherwise it is not liquefied.

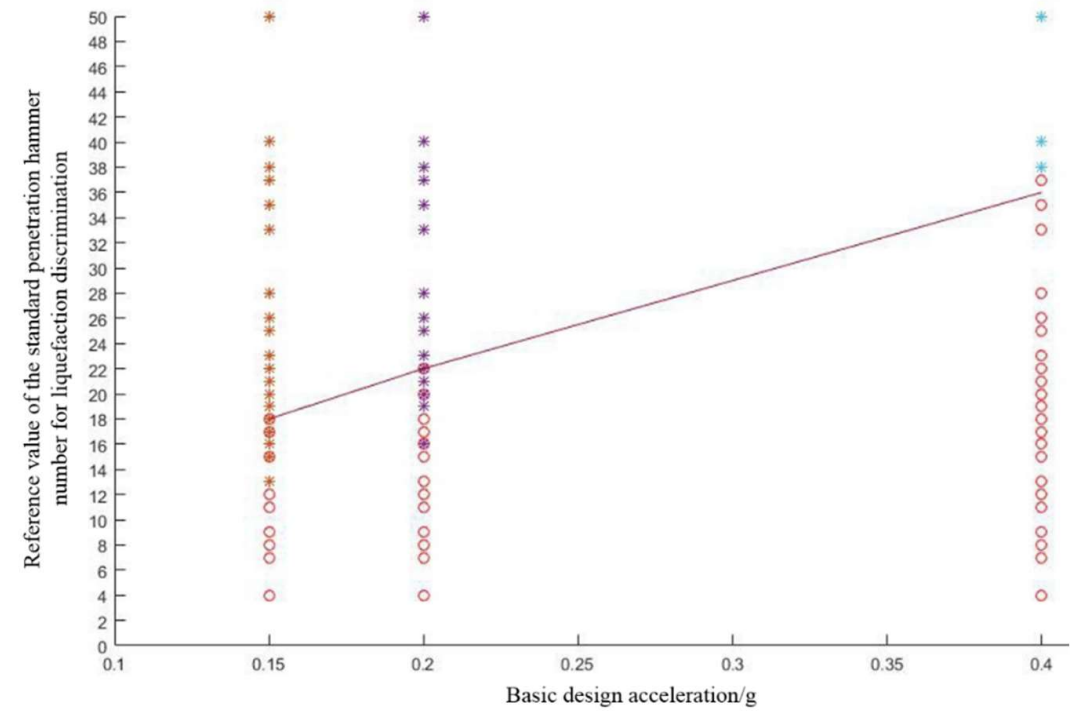

Fig. 1 The estimation of reference value about standard penetration hammer number

Table 3. $N^{\prime}$-value for different accelerations

\begin{tabular}{cccccc}
\hline Design basic acceleration $(\mathrm{g})$ & 0.10 & 0.15 & 0.20 & 0.30 & 0.40 \\
\hline $\begin{array}{c}\text { Reference value of the stand- } \\
\text { ard penetration hammer num- } \\
\text { ber for liquefaction discrimina- } \\
\begin{array}{c}\text { tion } \\
\hline\end{array}\end{array}$ & 15 & 20 & 23 & 29 & 35 \\
\hline
\end{tabular}

\section{Reliability analysis of the three hyperbolic discriminant formulas}

\subsection{Recovery analysis of Songyuan seismic data}

The hyperbolic liquefaction discriminant formula (Equation (3)) and the "Code for Seismic Design of Buildings (GB50011-2010 in China)" was applied to determine the liquefaction data for the Songyuan area (China), which were then compared and analyzed (Table 4). 
Table 4. Comparison between the success rates of the hyperbolic formula and the code method for the liquefaction data of Songyuan

\begin{tabular}{cccc}
\hline Method & $\begin{array}{c}\text { Total } \\
\text { samples }\end{array}$ & $\begin{array}{c}\text { Liquefac- } \\
\text { tion samples } \\
\text { (all) }\end{array}$ & $\begin{array}{c}\text { Non-lique- } \\
\text { faction sam- } \\
\text { ples (all) }\end{array}$ \\
\hline $\begin{array}{c}\text { Normative method } \\
\text { Hyperbolic discriminant formula }\end{array}$ & $88.5 \%$ & $100 \%$ & $85 \%$ \\
\hline
\end{tabular}

In Table 4, it can be shown as follows: both the hyperbolic discriminant formula and standard method performed very well (success rate for liquefaction point data $=100 \%$ ). However, for non-liquefaction point data, the success rate of the hyperbolic discriminant formula is $95 \%$ and that of the standard method is only $85 \%$, and the success rate of the hyperbolic discriminant formula was more balanced. Overall, these results indicate that the hyperbolic discriminant formula proposed in this paper has a good applicability to the liquefaction data of the Songyuan site compared with the existing standard method.

\subsection{Recovery analysis for Chinese mainland seismic data}

The hyperbolic liquefaction discrimination formula (Equation (3) and the "Code for Seismic Design of Buildings" (GB50011-2010) were applied to determine the liquefaction data of Chinese mainland areas [23]. Some information about the liquefaction discrimination and a comparison between the discriminant results are shown in Tables 5 and 6. The results indicate that, among 172 groups of liquefaction data, the success rates of the two different liquefaction discriminant formulas are similar. However, the success rate of the non-liquefaction discrimination through the hyperbolic discriminant formula is $74 \%$, while that obtained through the standard method is only $51 \%$. Under different intensity regions, the accuracy of the model for the liquefaction data is significantly higher than that of the standard method. Compared with the existing standard method, the proposed hyperbolic discriminant formula has a good applicability to the seismic liquefaction data of Chinese mainland sites.

Table 5. Comparison between the success rates of the hyperbolic formula and of the standard method in relation to the liquefaction data of the Chinese mainland

\begin{tabular}{cccc}
\hline Method & $\begin{array}{c}\text { Total } \\
\text { samples }\end{array}$ & $\begin{array}{c}\text { Liquefaction } \\
\text { samples (all) }\end{array}$ & $\begin{array}{c}\text { Non-liquefaction } \\
\text { samples (all) }\end{array}$ \\
\hline the standard method & $72 \%$ & $91 \%$ & $51 \%$ \\
hyperbolic discriminant formula & $86 \%$ & $95 \%$ & $74 \%$ \\
\hline
\end{tabular}


Table 6. Comparison between the success rate of the hyperbolic formula and of the standard method for liquefaction data collected in China under different intensities.

\begin{tabular}{cccc}
\hline Intensity region & Site situation & $\begin{array}{c}2010 \text { norma- } \\
\text { tive Law }\end{array}$ & Hyperbolic discriminant formula \\
\hline \multirow{2}{*}{ VII } & Liquefied & $100 \%$ & $100 \%$ \\
& No liquefaction & $52 \%$ & $80.4 \%$ \\
& Overall & $72.5 \%$ & $85 \%$ \\
LIII & Liquefied & $89 \%$ & $96.4 \%$ \\
& No liquefaction & $81 \%$ & $85.2 \%$ \\
& Overall & $85 \%$ & $89 \%$ \\
& Liquefied & $87.5 \%$ & $90 \%$ \\
& No liquefaction & $65 \%$ & $70 \%$ \\
& Overall & $80 \%$ & $83 \%$ \\
\hline
\end{tabular}

3.3. Test results of the new method for seismic liquefaction data during Bachu Earthquake

In this paper, Forty-seven sets of Bachu earthquake data [28-29] was collected and sorted out, which include 21 and 26 sets of liquefaction and non-liquefaction data, respectively.

As a whole, the success rate of the liquefaction discrimination done through the hyperbolic discriminant formula is lower than done through the normative method in (results shown in Table 7). For the different degree intensity region, the success rate of liquefaction discrimination of hyperbolic discriminant formula is lower than that of normative method, however, that the success rate of the non-liquefaction discrimination done through the hyperbolic discriminant formula is higher than that obtained through the normative law, and the success rate of the overall discriminant is lower. Comparison of two discriminative methods from VII, VIII and IX degrees, these results show that the normative law is more suitable for determining the liquefaction during the Bachu earthquake, and the success rates of the liquefaction discrimination are higher.

Table 7. Success rates of the two methods applied to the Bachu earthquake

\begin{tabular}{cccc}
\hline Intensity region & Liquefaction & Normative law & Hyperbolic discriminant formula \\
\hline \multirow{2}{*}{ VII } & Liquefied & $57 \%$ & $14 \%$ \\
& No liquefaction & $100 \%$ & $100 \%$ \\
& Overall & $75 \%$ & $50 \%$ \\
\multirow{2}{*}{ VIII } & Liquefied & $62.5 \%$ & $50 \%$ \\
& No liquefaction & $86.7 \%$ & $100 \%$ \\
& Overall & $65 \%$ & $82.6 \%$ \\
IX & Liquefied & $100 \%$ & $66.7 \%$ \\
& No liquefaction & $50 \%$ & $83 \%$ \\
& Overall & $75 \%$ & $75 \%$ \\
\hline
\end{tabular}




\subsection{Test results of the new method for New Zealand seismic data}

In this paper, 195 groups of seismic data (including 147 and 48 sets of liquefaction and non-liquefaction data, respectively) from New Zealand were collected [30].

The hyperbolic discriminant formula was applied to these data, and its results were compared to those of the standard method (results shown in Table 8). For the VIII intensity region, the success rates of the hyperbolic discriminant formula and of the standard method are very different. As a matter of fact, the above results of the both discriminant methods are consistent with those of sandy soil liquefaction in the VIII intensity region of the New Zealand earthquake. Meanwhile, the hyperbolic discriminant formula seemed more suitable for judging sand liquefaction in the IX intensity region of the New Zealand earthquake. Furthermore, the building seismic design code could not judge satisfactorily the liquefaction in the $\mathrm{X}$ degree intensity region; however, when establishing the hyperbolic discriminant formula, the basic database contained the liquefaction point of X degree. Comparison of VIII, IX and X degrees the hyperbolic discriminant formula was found to be more suitable for judging the sand liquefaction intensity region of the New Zealand earthquake.

Table 8. Success rates of the two methods for the New Zealand earthquake

\begin{tabular}{cccc}
\hline $\begin{array}{c}\text { Intensity re- } \\
\text { gion }\end{array}$ & Liquefaction & $\begin{array}{c}\text { Normative } \\
\text { law }\end{array}$ & $\begin{array}{c}\text { Hyperbolic discrimi- } \\
\text { nant formula }\end{array}$ \\
\hline \multirow{3}{*}{ VIII } & Liquefied & $84.2 \%$ & $81.6 \%$ \\
& No liquefac- & $100 \%$ & $100 \%$ \\
tion & & \\
& Overall & $85 \%$ & $82.5 \%$ \\
LX & Liquefied & $99.5 \%$ & $96.2 \%$ \\
& No liquefac- & $43.7 \%$ & $93.0 \%$ \\
& tion & & $95.4 \%$ \\
Overall & $85.4 \%$ & $100 \%$ \\
L-ray & No liquefied & & \\
& tion & & $100 \%$ \\
\hline
\end{tabular}

\section{Discussion and conclusion}

Based on the study of the Songyuan site and relevant seismic data, the sand liquefaction discrimination method was studied. The discriminant formula for sand liquefaction was established using the hyperbolic model in soil dynamics, and some results have been achieved. The main conclusions of this paper are as follows:

The reliability of the hyperbolic discriminant formula proposed in this paper was tested and compared with the discriminant results of the standard method. The results show that the discriminant success rate of the hyperbolic discriminant formula is higher than that of the standard method, and its results could better reflect the actual liquefaction at the study site. When applied to different intensity regions, the success rate of the hyperbolic liquefaction discriminant formula is always higher than that of the standard method, showing that the hyperbolic discriminant formula has a higher accuracy.

Due to the uncertainty of sand liquefaction and the complexity of geological conditions at engineering sites, the current discrimination method is based on survey data of liquefaction damage collected in specific areas or where major earthquakes occurred. As 
a matter of fact, effective seismic damage data are relatively few and there are some regional limitations. Therefore, it is necessary to establish a regional discriminant method

\section{References}

1. Huang Yu, YU Miao, BHATTACHARYA Subhamoy. 2013.Summary of earthquake induced liquefaction in the Pacific Ocean of the Northeast Japan in 2011[J]. Chinese Journal of Geotechnical Engineering, 35(05): 834-840. (in Chinese)

2. YOUD T L, IDRISS I M. 2001.Liquefaction resistance of soil: report from the 1996 NCEER and 1998 NCEER/NSF workshops on evaluation of liquefaction resistance of soils[J]. Journal of Geotechnical and Geoenviromental Engineering, American Society of Civil Engineering, 127(4): 297-313.

3. IDRISS I M, BOULANGER R W.2008. Soil liquefaction during earthquakes[M]. Davis: Earthquake engineering research institute.

4. ROBERTSON P K, WRIDE C E. 1997.Cyclic Liquefaction and Its Evaluation Based on the SPT and CPT[R]. NY: NCEER-970022, Buffalo.

5. FU Hai-qing, YUAN Xiao-ming, WANG Miao. 2018. An incremental model of pore pressure for saturated sand based on in-situ liquefaction test[J]. Rock and Soil Mechanics, 39(5): 1611-1618. (in Chinese)

6. LIU Han-long, WANG Wei-guo, LIU Jun, et al.2017. Large-scale field tests on blast-induced liquefaction in saturated sand[J]. Chinese Journal of Geotechnical Engineering, 39(4): 601-608. (in Chinese)

7. SHI Zhaoji, ZHANG Rongxiang, GU Baohe.1997. Study on comprehensive method of sand liquefaction discrimination and evaluation[J]. Earthquake engineering and Engineering Vibration, (01):83-89. (in Chinese)

8. Wang Liang, BO Jingshan, LI Xiaobo, et al.2017. Some progress in the study of liquefaction discrimination methods of sand. World Earthquake Engineering, 33(04): 141-150. (in Chinese)

9. LI Ping, TIAN Zhaoyang, BO Jingshan, et al. 2019.Study on sand liquefaction of the magnitude-5.7 Songyuan earthquake[J]. Journal of Civil Engineering, 52(09): 91-99. (in Chinese)

10. National Institute of Building Research. 1979. Code for seismic design of industrial and civil buildings (TJ11-78) [S]. Beijing: China Construction Industry Press. (in Chinese)

11. Ministry of Housing and Urban-Rural Development of the People's Republic of China. 2010. Code for seismic design of buildings (GB50011-2010) [S], Beijing: China Construction Industry Press. (in Chinese)

12. The former Ministry of Urban and Rural Construction and Environmental Protection of the People's Republic of China.1989. Code for seismic design of buildings (GBJ11-89) [S], Beijing: China Construction Industry Press. (in Chinese)

13. Ministry of Construction of the People's Republic of China. 2001. Code for seismic design of buildings (GB50011-2001) [S], Beijing: China Construction Industry Press. (in Chinese)

14. SHI Zhaoji, YU Shousong, FENG Wanling.1993. Discrimination of soil liquefaction potential by shear wave velocity[J]. Journal of geotechnical engineering, (01): 74-80. (in Chinese)

15. Ministry of Construction of the People's Republic of China .2009. Code for investigation of Geotechnical Engineering (GB50021-2001) [S]. Beijing: China Building Industry Press. (in Chinese)

16. Ministry of Housing and Urban-Rural Development of the People's Republic of China.2008. Code for geological investigation of water conservancy and Hydropower Engineering (GB50487-2008) [S]. Beijing: China Planning Press. (in Chinese)

17. National Railway Administration.2003. Code for in situ test of Railway Engineering Geology (TB10018-2003) [S]. Beijing: China Railway Press, 2003. (in Chinese)

18. WANG Wenshao.1984. Discussion on liquefaction mechanism and discrimination method of saturated sand[C]. Scientific research papers of water conservancy and Hydropower Research Institute. Beijing: Water conservancy and electric power press. (in Chinese)

19. Yound T L, Idriss I M, Ronald D, et al. 2001.Liquefaction Resistance of Soils: Summary Report from the 1996 NCEER and 1998 NCEER/NSF Workshops on Evaluation of Liquefaction Resistance of Soils[J]. Journal of Engineering, ASCE, 127(10): 817-833.

20. Seed H B, Idriss I M. 1971.Simplified procedure for evaluating soil liquefaction potential[J]. Journal of Soil Mechanics \& Foundations Division.

21. Fukutakek, Ohtsuki A, Sato M, et al. 1990.Analysis of saturated dense sand-structure system and comparison with results from shaking table test[J]. Earthquake Engineering \& Structural Dynamics, 19(7) : 977-992.

22. BS EN 1998-5: 2004 Eurocode 8: Design of Structures for Earthquake Resistance, Part 5: Foundation, Retaining Structure and Geotechnical Engineering[S]. London: BSI.

23. XIE Junfei. 1984. Some opinions on modifying the criterion of sand liquefaction in seismic code[J]. Earthquake engineering and Engineering Vibration, 4(02):95-126 (in Chinese)

24. SUN Rui, ZHAO Qianyu, YUAN Xiaoming.2014. Hyperbolic model of liquefaction discrimination[J]. Journal of geotechnical engineering, 36(11): 2061-2068. (in Chinese)

25. ZHAO Qianyu.2013. Study on improvement of standard penetration liquefaction discrimination method in China[D]. Institute of engineering mechanics, China Seismological Bureau. (in Chinese)

26. SUN Rui, YUAN Xiaoming. 2019.Discrimination formula of shear wave velocity suitable for liquefaction of soil layers with different depths[]]. Journal of geotechnical engineering, 41(03): 439-447. (in Chinese) 
27. SUN Rui, LI Xiaofei, CHEN Longwei, et al.2018.Study on the parameters of hyperbolic model with increasing pore pressure[J]. Vibration and shock, 37(07): 1-7. (in Chinese)

28. LI Zhaoyan, YUAN Xiaoming, CAO Zhenzhong, et al. 2012. Based on Bachu earthquake survey in Xinjiang, a new 